\title{
Long-Lasting Psychotomimetic Consequences of Repeated Low-Dose Amphetamine Exposure in Rhesus Monkeys
}

\author{
Stacy A. Castner, Ph.D., and Patricia S. Goldman-Rakic, Ph.D.
}

The dopamine hypothesis of schizophrenia posits that dopamine dysregulation plays a key role in the etiology of schizophrenia. In line with this hypothesis, repeated amphetamine (AMPH) exposure has been shown to alter dopamine systems and induce behaviors reminiscent of positive-like and negative-like symptoms in both human and nonhuman primates. The mechanisms by which AMPH produces disturbances in brain function and behavior are not fully understood. The present study has employed a novel AMPH regimen, 12 weeks of intermittent escalating low doses of AMPH, to produce a nonhuman primate model for the purpose of elucidating the behavioral and neural consequences of excessive dopamine exposure. Behavioral responses to acute AMPH challenge (0.4-0.46 $\mathrm{mg} / \mathrm{kg}$ ) were assessed prior to and following the chronic 12week treatment regimen, and, at present monkeys have been followed out to 28 months post-treatment. After chronic treatment, enhanced behavioral responses to $A M P H$ challenge were readily apparent at 5 days postwithdrawal, and, were still present at 28 months postwithdrawal. The enhanced behavioral responses to low-dose AMPH challenge that were observed in the present study resemble closely the behavioral profile that has been described for chronic high-dose AMPH treatment in monkeys; i.e., hallucinatory-like behaviors, static posturing, and finemotor stereotypies were all exacerbated in response to AMPH injection. In some animals, acute challenges after chronic AMPH evoked aberrant behavioral responses that lasted for 4 days. AMPH-treated monkeys also exhibited a significant decrease in the incidence of motor stereotypies in the off-drug periods between challenges. The present results are the first to document persistent long-term behavioral effects of intermittent exposure to repeated low-dose AMPH treatment in nonhuman primates. These findings may lay the groundwork for the development of a primate mode of psychosis with possible positive-like and negative-like symptoms.

[Neuropsychopharmacology 20:10-28, 1999] (c) 1998 American College of Neuropsychopharmacology. Published by Elsevier Science Inc.
KEY WORDS: Schizophrenia; Primates; Sex differences; Animal model; Stimulants; Behavioral sensitization

Repeated amphetamine (AMPH) use in humans can induce behaviors reminiscent of paranoid schizophrenia

From the Yale University School of Medicine, Section of Neurobiology, New Haven, Connecticut.

Address correspondence to: Stacy A. Castner, Ph.D., Yale University School of Medicine, Section of Neurobiology, 333 Cedar Street, New Haven, CT 06510.

Received 15 January 1998; revised 14 May 1998; accepted 20 May 1998. (e.g., Angrist 1994). Chronic AMPH treatment in nonhuman primates also induces a characteristic pattern of behavioral response that has been likened to paranoid schizophrenia in humans (e.g., Ellison 1994; Ellison et al. 1981; Ridley et al. 1982). Behaviors typically shown by monkeys undergoing chronic AMPH treatment include extreme vigilance, tracking of nonapparent stimuli, constant checking, startle responses in the absence of visible/audible stimuli, grasping in midair, and hyper-responsiveness to sensory stimuli (Ridley et al. 1982). This behavioral repertoire is reminiscent of positive-like symptoms in schizophrenic patients. 
Negative-like symptoms of schizophrenia have also been observed during chronic AMPH treatment in monkeys. One hallmark negative symptom of schizophrenia is the psychomotor poverty syndrome (Liddle et al. 1992). In monkeys, Schlemmer et al. (1996) have shown that chronic AMPH treatment results in a significant decrease in motor stereotypies. Other studies have found that some monkeys treated with chronic AMPH exhibit catatonic-like states; for example, sitting frozen in one spot while staring off into space for extended periods of time (Ellison et al. 1981).

The aforementioned studies on the behavioral consequences of $\mathrm{AMPH}$ in monkeys were all conducted during chronic and/or high-dose AMPH exposure. One of the drawbacks of chronic AMPH animal models of psychosis is that they induce neurotoxicity of the nigrostriatal dopamine system (Ridley et al. 1983; Ellison and Ratan 1982; Ellison et al. 1978). In rodents, it has been shown that nigrostriatal neurotoxicity can be avoided if AMPH treatment consists of repeated, intermittent low-dose exposure to the drug. Compared to chronic and high-dose regimens, escalation of low doses permits neuronal adaptation and more closely models drug use in human AMPH addicts (Robinson and Becker 1986).

Taking our lead from the rodent literature, and in light of the fact that there is very little evidence of profound or long-lasting dopamine dysfunction resulting from repeated, intermittent AMPH use in humans, we have investigated the long-term behavioral consequences of a similar treatment regimen in rhesus monkeys (Wilson et al. 1996). Although there are data from positron emission tomography (PET) studies in nonhuman primates indicating that neuronal depression can occur in response to acute AMPH injections (Melega et al. 1997; Villemagne et al. 1998), the starting dose (0.1 $\mathrm{mg} / \mathrm{kg}$ ) of AMPH used in the chronic phase of the present experiment was 5 to 20 times lower than the doses used in the imaging studies. Nevertheless, it is our ultimate intention to examine the brains of the monkeys in the present study to determine whether neurotoxicity was produced by the intermittent treatment regimen.

The primary goal of the present manuscript is to determine the psychotomimetic consequences of chronic $\mathrm{AMPH}$ treatment both off drug and in response to acute, periodic low-dose AMPH challenge. If this regimen in nonhuman primates results in enhanced behavioral responses to subsequent AMPH challenge, and furthermore, these responses resemble those described above for chronic high-dose AMPH treatments in monkeys, then the escalating low-lose AMPH regimen used in the present study may produce a potentially valuable animal model of psychosis.

\section{MATERIALS AND METHODS}

\section{Subjects}

Subjects included five young adult male and five young adult female rhesus monkeys (Macaca mulatta) ranging in age from 4 to 8 years. Two of the females were used for histology (see below). Monkeys were maintained in single-unit housing (male cages: 35 -in $\mathrm{h} \times 26$-in $\mathrm{d} \times 4$-in $\mathrm{w}$; female cages 30 -in $\mathrm{h} \times 26$-in $\mathrm{d} \times 23.5$-in $\mathrm{w})$ on a 12:12 light dark cycle (lights on 7 A.M. -7 P.M.). Monkeys were provided with typical enrichment devices including: monkey-tested dog toys, logs, and plastic chains. New dog toys and chains were provided with cage rotation every 2 weeks. Logs, on the other hand, remained unchanged. Water was available ad libitum, and monkeys received 30 biscuits of standard high-fiber monkey chow, fruit, and peanuts each day. Food intake was monitored daily. Animals were taken care of in accordance with Yale Animal Use and Care Committee guidelines for nonhuman primates.

\section{Drugs and Antibodies}

$\mathrm{S}(+)$-amphetamine sulfate was purchased from RBI (Natick, MA). For injections, amphetamine was dissolved in sterile saline solution. All injections were given IM AMPH doses referred to below are based on weight of salt and were administered to monkeys in $\mathrm{mg} / \mathrm{kg}$. Antibodies, a monoclonal mouse antityrosine hydroxylase (1:1000) and a monoclonal rat antidopamine transporter $(1: 10,000)$, were obtained from Chemicon (Temucula, CA).

\section{Baseline Behavioral Observations}

Monkeys were observed twice daily (Monday-Friday) in their home cage over a period of 3 to 6 months to establish a baseline behavioral profile for each monkey and document early day (10 A.M.-2 P.M.) and late day (5:30-8:00 P.M.) differences in behavior. On average, three to four monkeys were observed during a given session. Data were collected using a focal time-sampling procedure (2.5 min per monkey) on a Macintosh computer with a program, Monkey Watcher, designed especially for this purpose. For a given session, each monkey was observed for no less than 10 minutes. While manually operated, Monkey Watcher allows for documentation of the total duration, frequency, number of occurrences, and average duration of a given behavior. Twenty-four behaviors were assigned to keys on the keyboard; 23 keys were assigned specific behaviors (for a list of specific behaviors see left side of Table 1). The 23 behaviors assigned to specific keys on the keyboard were based on several weeks of observations of 
Table 1. Keyboard Behaviors

\begin{tabular}{ll}
\hline 1. Call & 24. Etcetera examples \\
2. Circle & $\bullet$ parasitosis \\
3. Stand & $\bullet$ lie on side \\
4. Eat & $\bullet$ repetitive grasp \\
5. Groom & $\bullet$ buccolingual dyskinesia \\
6. Side-to-side & $\bullet$ hold bars \\
7. Threaten/challenge & $\bullet$ vacuous mouth movements \\
8. Grunt & $\bullet$ swat at nothing \\
9. Lipsmack & $\bullet$ track/orient to nothing \\
10. Drink & $\bullet$ grasp at air \\
11. Present & $\bullet$ two or one arm stretch \\
12. Pace & $\bullet$ inspect hands/arms \\
13. Self-bite & $\bullet$ stare space \\
14. Reach & $\bullet$ cling to bars \\
15. Sit & $\bullet$ one arm twirl \\
16. Scan & $\bullet$ fiddle with bars \\
17. Respond-to-stimulus & $\bullet$ sniff fingers \\
18. Watch/stare & \\
19. Crouch & \\
20. Masturbate & \\
21. Scratch & \\
22. Play & \\
23. Cage shake &
\end{tabular}

monkeys in their home cages prior to the start of data collection for the present study. The twenty-fourth key was designated "etcetera," and behaviors not assigned to one of the 23 specific keys were recorded by hand while the etcetera key was depressed. Many etcetera behaviors predominated only after AMPH administration and were unique to each monkey (note: some examples of etcetera behaviors relevant to the present manuscript are listed on the right side of Table 1). Behaviors from Table 1 are categorized in Table 2, and the eight behavioral categories defined in Table 2 are used throughout this manuscript. Two experimenters conducted observations during the first 8 months of the study. However, because of the extraordinary time demands of this project, only one observer was available on a daily basis for the latter stages of the experiment. From the baseline data, animals were assigned to either the experimental $(n=6)$ or control group $(n=2)$. An attempt was made to ensure that animals exhibiting high levels of stress behaviors under baseline conditions; for example, self-biting; self-grasping, and such motor stereotypies as pacing, circling, side-to-side, were distributed equally between groups (see Table 3).

\section{Serum Dose Response}

Prior to chronic AMPH administration, multiple serial blood draws were performed to examine possible group/sex/individual differences in AMPH metabolism. Specifically, monkeys in the experimental or
AMPH group $(n=6)$ underwent three serial blood draw sessions. For the AMPH group, a dose-response curve was obtained (three doses of AMPH given at 1 month intervals to allow for recovery from phlebotomy). Animals first received $0.1 \mathrm{mg} / \mathrm{kg}$ AMPH IM, and serum samples were taken at timed intervals $(5 ; 15 ; 30$; $45 ; 60 ; 90 ; 120 ; 150 ; 180 \mathrm{~min})$ postinjection. One month later, they received $0.8 \mathrm{mg} / \mathrm{kg}$ AMPH IM. AMPH concentrations in serum tended to peak at approximately 15 minutes postinjection coincident with peak elevation in heart rate in response to AMPH. The third midrange dose of AMPH varied $(0.4-0.46 \mathrm{mg} / \mathrm{kg}$; IM) based on the variability between individuals in serum concentrations of AMPH at the 15 minute (peak) time point for the two previous doses. To control for any untoward effects of ketamine restraint, isoflurane anesthesia, and phlebotomy, control animals were restrained once and subjected to the same procedure, but instead of receiving an AMPH injection they received saline. During blood draws, serum samples were also taken to look at possible effects of AMPH/sex on serum cortisol and prolactin (PRL) concentrations.

\section{Prechronic Treatment Behavioral Dose Response}

Following completion of the serum dose-response curve, behavioral baseline was re-established for each monkey. Next, behaviors were recorded as described above (see baseline behavioral observations) by means of a computer and on video for each animal at the same doses of AMPH that were administered in the serum analysis phase (saline; $0.1 ; 0.4-0.46 ; 0.8 \mathrm{mg} / \mathrm{kg} \mathrm{AMPH}$; IM). Focal time-sampling techniques were used to obtain behavioral observations for a minimum of 2 hours following each injection and at timed intervals thereafter, including: 6 to 8 hours postinjection; 24 hours postinjection, and as needed to allow for behavior to return to baseline. To achieve each curve, doses of $\mathrm{AMPH}$ were administered in ascending order, because there was the potential for behavioral enhancement with each subsequent injection of AMPH. During this phase, an adequate washout time, 2 weeks, was permitted between AMPH injections. AMPH animals were always paired with saline-treated controls. On challenge days, controls received an injection of the vehicle, $0.9 \% \mathrm{NaCl}$, by weight.

\section{Chronic AMPH Treatment}

Animals were subjected to an escalating intermittent low-dose binge regimen of AMPH modified from protocols that have been used to produce behavioral sensitization in rodents (e.g., Paulson et al. 1991). Monkeys 
Table 2. Behavioral Categories

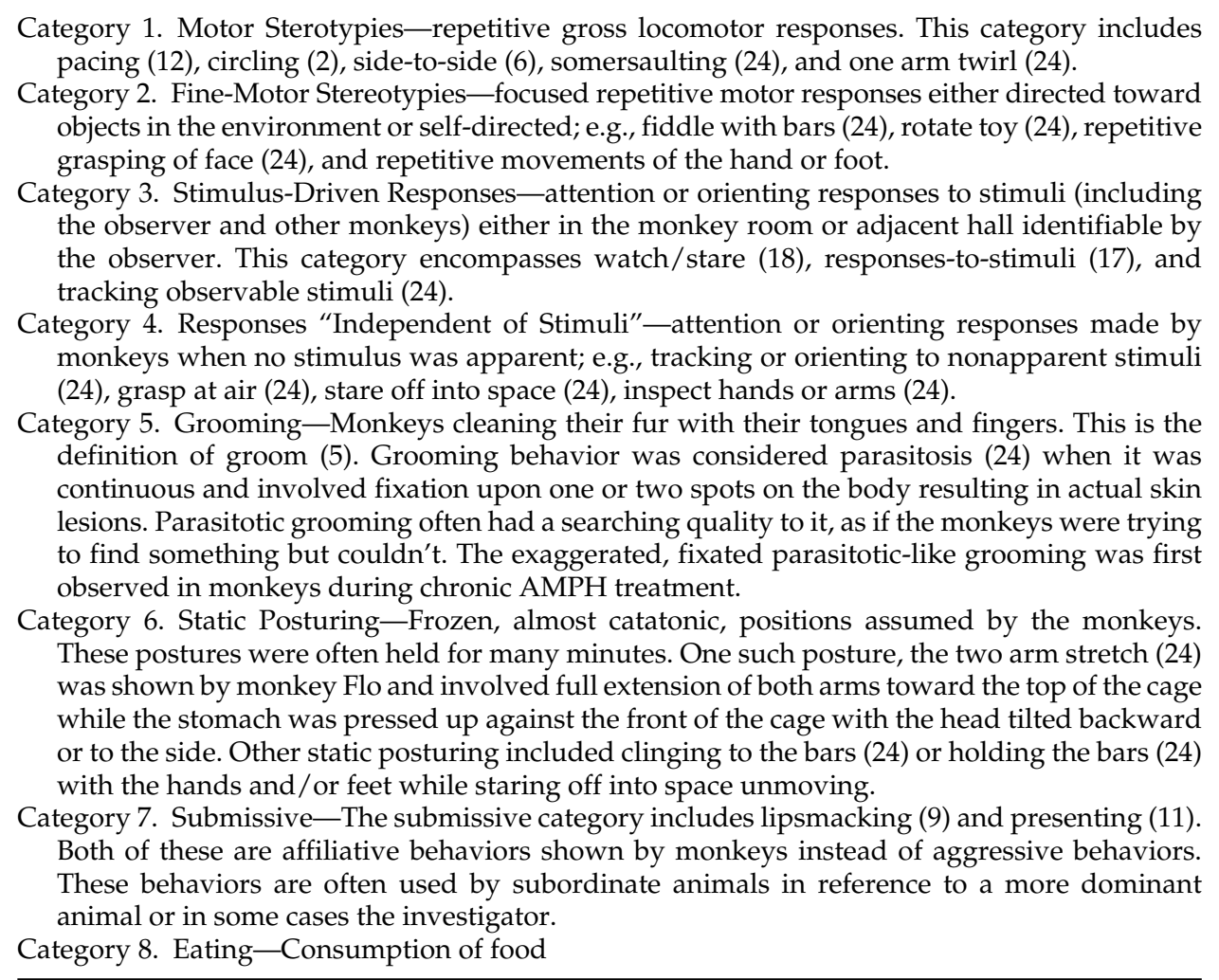

received twice daily injections of $\mathrm{AMPH}$ or saline 5 days per week (weekends off) for 12 weeks. The dose of AMPH was increased by increments of $0.1 \mathrm{mg} / \mathrm{kg}$ at approximately regular intervals over the 12-week period (starting dose $0.1 \mathrm{mg} / \mathrm{kg}$; ending dose $1.0 \mathrm{mg} / \mathrm{kg}$ AMPH). During chronic AMPH, the monkey's behaviors at each dose were recorded on computer and on videotape. With the exception of a 10 to 12 day period when the investigator was out of town, the monkeys were observed once or twice 5 days per week immediately following $\mathrm{AMPH}$ injection and once daily on the weekends during the 12 weeks of chronic AMPH treatment. The weekend observations were intended to document any signs of withdrawal.

\section{Postchronic Treatment Behavioral Observations/ Dose Response}

Monkeys were observed once or twice daily in their home cage during the first 21 days postchronic $\mathrm{AMPH}$ treatment for signs of withdrawal, including psychomotor depression. Animals in the experimental group received AMPH challenges (0.4-0.46 $\mathrm{mg} / \mathrm{kg} \mathrm{IM})$ on days 5, 11 (or 12, see Results section), and 21 of withdrawal. After this time, a behavioral dose-response curve was performed in the same manner as described above for the prechronic treatment phase. Animals also received discrete challenges of AMPH $(0.4-0.46 \mathrm{mg} / \mathrm{kg}$ IM) at 6, 9, and 12 months postwithdrawal and periodically thereafter to monitor long-lasting behavioral con-

Table 3. Baseline Behavorial Profiles

\begin{tabular}{|c|c|c|c|c|c|c|c|c|}
\hline $\begin{array}{l}\text { Monkey } \\
\text { Name }\end{array}$ & $\begin{array}{c}\text { Motor } \\
\text { Stereotypies }\end{array}$ & $\begin{array}{l}\text { Fine-Motor } \\
\text { Stereotypies }\end{array}$ & $\begin{array}{l}\text { Stimulus- } \\
\text { Driven } \\
\text { Responses }\end{array}$ & $\begin{array}{l}\text { Responses } \\
\text { "Independent } \\
\text { of Stimuli" }\end{array}$ & Grooming & $\begin{array}{c}\text { Static } \\
\text { Posturing }\end{array}$ & Submissive & Eating \\
\hline Flo (f) & $26.53 \pm 3.55$ & & $19.07 \pm 3.97$ & & & $0.57 \pm 0.31$ & $0.18 \pm 0.13$ & $=3.77$ \\
\hline Vien (f) & $21.56 \pm 3.79$ & $0.01 \pm 0.01$ & $14.06 \pm 2.24$ & $0.42 \pm 0.42$ & $3.98 \pm 1.84$ & $0.20 \pm 0.17$ & $0.04 \pm 0.03$ & $27.57 \pm 4.57$ \\
\hline $\operatorname{Jag}(\mathrm{m})$ & $43.59 \pm 3.00$ & $0.08 \pm 0.08$ & $18.00 \pm 2.38$ & $0.13 \pm 0.09$ & $0.32 \pm 0.18$ & $0.00 \pm 0.00$ & $0.04 \pm 0.04$ & $16.65 \pm 2.33$ \\
\hline Glas (m) & $3.57 \pm 1.36$ & $0.00 \pm 0.00$ & $17.20 \pm 2.88$ & $0.00 \pm 0.00$ & $1.95 \pm 1.30$ & $2.00 \pm 1.15$ & $1.35 \pm 0.72$ & $24.64 \pm 5.46$ \\
\hline Mad (m) & $0.54 \pm 0.50$ & $0.00 \pm 0.00$ & $7.15 \pm 1.59$ & $0.00 \pm 0.00$ & $0.46 \pm 0.21$ & $0.08 \pm 0.08$ & $0.00 \pm 0.00$ & $51.67 \pm 5.26$ \\
\hline $\operatorname{Kram}(\mathrm{m})$ & $15.77 \pm 2.55$ & $0.00 \pm 0.00$ & $21.12 \pm 2.83$ & $0.00 \pm 0.00$ & $2.69 \pm 1.22$ & $0.29 \pm 0.14$ & $0.03 \pm 0.02$ & $16.76 \pm 3.12$ \\
\hline
\end{tabular}


sequences of treatment. For all AMPH challenges, behavioral responses were recorded on computer and on video. Additional AMPH challenges are ongoing as part of a longitudinal study. Following AMPH challenge, monkeys were observed at regular intervals until an animal's behavior returned to its prechallenge "baseline" level, referred to from here on as prechallenge behavior to distinguish it from prechronic treatment (baseline) behavior.

\section{Four-Week AMPH Pilot Study}

One female monkey was subjected to a 4-week escalating, intermittent, low-dose treatment regimen of AMPH. This monkey received the same doses of AMPH as the 12-week monkeys, but the doses were escalated more rapidly. The home cage behavior of this monkey was recorded before and after chronic treatment in response to $0.4 \mathrm{mg} / \mathrm{kg}$ AMPH challenge for signs of behavioral enhancement.

\section{Immunocytochemistry}

Three months after withdrawal and 1 week post-AMPH challenge, the 4-week AMPH-treated monkey was restrained with ketamine, subjected to an overdose of pentobarbital anesthesia, and then perfused transcardially with phosphate-buffered saline. During the saline flush, a frontal lobectomy was performed on one hemisphere to obtain fresh tissue for biochemical analysis. Next, perfusion was continued with a $4 \%$ paraformaldehyde solution with $0.2 \%$ glutaraldehyde and $15 \%$ picric acid. Tissue from an age-matched control (AMPH-naive) monkey was processed in the same manner. Immediately following the perfusions, the brains were removed, blocked, and sunk in $20 \%$ sucrose for several days. Tyrosine hydroxylase (TH) and dopamine transporter (DAT) immunocytochemistry were performed on cryostat obtained sections in accordance with previously published protocols from this laboratory (Krimer et al. 1997).

\section{Serum Analysis}

Serum AMPH and cortisol values were determined by National Psychopharmacology Laboratories (Knoxville, TX). Prolactin values were obtained from Metro Reference Labs (St. Louis, MO) in conjunction with National Psychopharmacology Laboratories.

\section{Data Analysis}

For serum data, two-way analysis of variance (ANOVA) with repeated measures was used where appropriate to identify sex differences and effects of time postinjection on serum concentrations. Factorial ANOVA was employed to identify sex differences in basal serum hormonal concentrations. Psychomotor depression data postchronic AMPH treatment for individual monkeys were analyzed by one-way factorial ANOVA.

\section{RESULTS}

\section{Baseline Behavioral Observations}

Table 3 shows the mean percentage time ( \pm SEM) each of the six monkeys spent engaged in the eight behavioral categories across 30 to 40 baseline samples (four monkeys were later assigned to the AMPH group and two to the control group). Individual differences were particularly evident in motor stereotypies (Category I). For example, monkeys Jag, Vien, Flo, and Kram exhibited high levels of motor stereotypies (pacing or circling) before AMPH (or saline) treatment; whereas, the two other monkeys, Mad and Glas, rarely displayed these behaviors. In other behavioral categories, however, there was more uniformity across individuals. For example, all animals spent approximately 7 to $21 \%$ of their baseline time engaged in stimulus-driven responses (Category III, Tables 2 and 3), and none, on the other hand, exhibited responses "independent of stimuli" (Category IV). Submissive behaviors (Category VII, presenting and lipsmacking) were also displayed relatively infrequently. Similarly, static posturing (Category VI) was rarely observed during baseline for any monkey. Although intersubject variability was high for motor stereotypies, intrasubject variability in baseline behaviors was minimal across days/months for all monkeys (see Means \pm SEM's for each monkey for each behavioral category in Table 3).

\section{Serum Concentrations of Amphetamine}

The challenge doses of AMPH used in this study (see below) were established by data from serum doseresponse studies done before chronic AMPH administration. At the $0.1 \mathrm{mg} / \mathrm{kg}$ dose of $\mathrm{AMPH}$, time following injection was highly significant $(\mathrm{F}[1,8]=4.663 ; p=$ .0043; Figure 1A). There was a nonsignificant $(\mathrm{F}[1,8]=$ 2.292; $p=.0752)$ trend for serum AMPH concentrations to peak earlier in females (15-90 $\mathrm{min})$ than in males (120 $\mathrm{min})$. For the second AMPH dose $(0.8 \mathrm{mg} / \mathrm{kg}), \mathrm{AMPH}$ concentrations in serum peaked at 30 and $45 \mathrm{~min}$ postinjection for females and males, respectively $(\mathrm{F}[1,8]=$ 3.15; $p=.0242$; see Figure 1A). Although females had higher AMPH serum concentrations across the 1st hour after injection as compared to males $(\mathrm{F}[1,2]=30.876$; $p=.0309)$, the over-all pattern of the serum AMPH response across time did not differ for males and females 

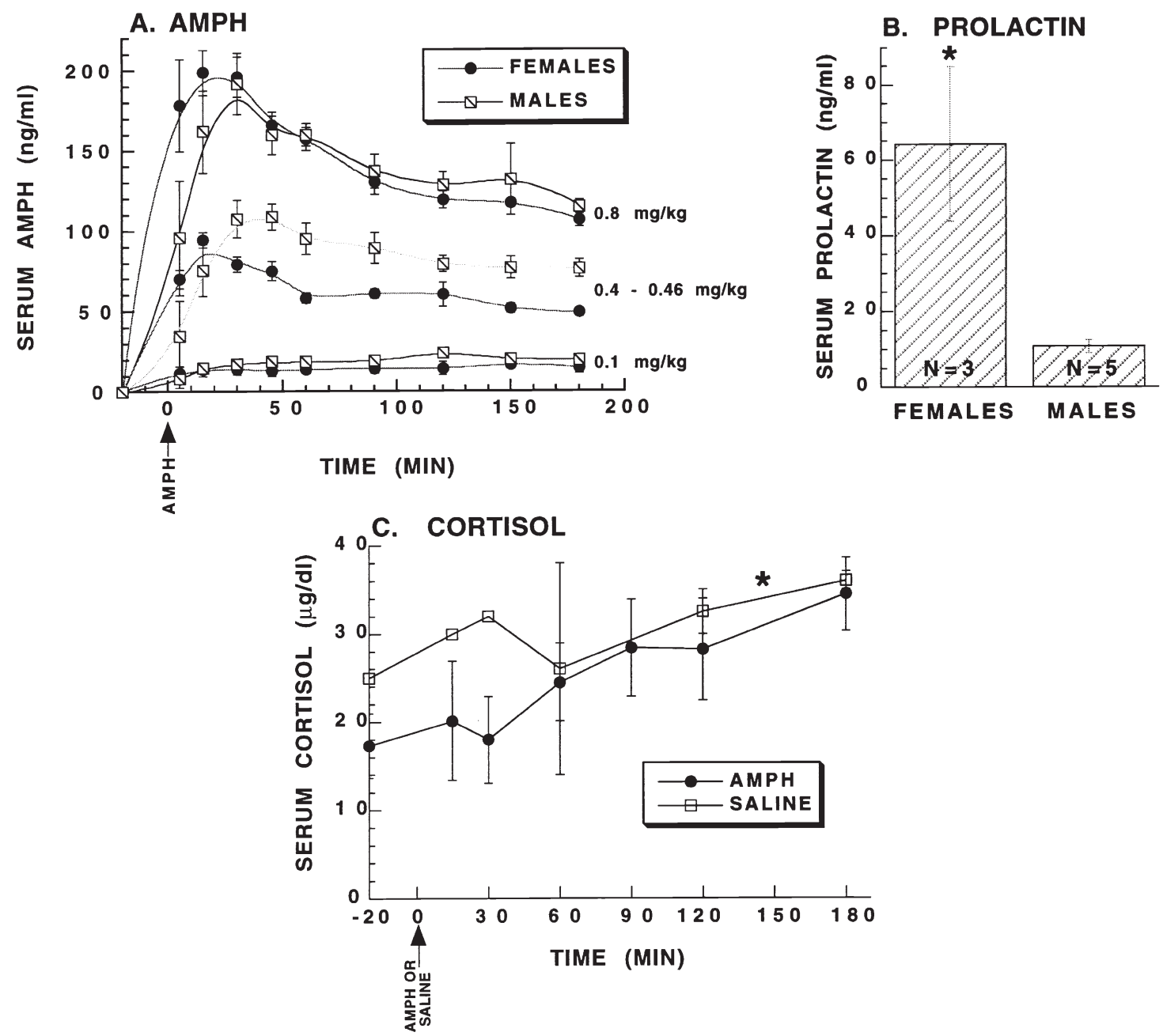

Figure 1. Serum AMPH concentrations for males and females across time following injection of three different doses of AMPH $(0.1,0.4$ to $0.46,0.8 \mathrm{mg} / \mathrm{kg})$. In response to $0.1 \mathrm{mg} / \mathrm{kg} \mathrm{AMPH}$, no sex differences were detected, but there was a significant effect of time postinjection on AMPH concentrations in serum (effect of sex: $\mathrm{F}[1,2]=0.376$; $p=.6023$; effect of time: $\mathrm{F}[1,8]=4.663 ; p=.0043$ ). Serum AMPH concentrations tended to peak slightly earlier in females than they did in males following $0.8 \mathrm{mg} / \mathrm{kg} \mathrm{AMPH}, 30$ and 45 minutes postinjection, respectively. Following the 0.4 to $0.46 \mathrm{mg} / \mathrm{kg}$ AMPH injections, there was a significant sex $\times$ time interaction. Although males tended to have lower serum AMPH concentrations during the first two samples postinjection, they had significantly higher serum AMPH concentrations during the 2nd and 3rd hours after injection as compared to the females (see text for statistics). Figure 1B shows that intact female rhesus monkeys had significantly high basal serum PRL concentrations than did intact males $\left(\mathrm{F}[1,4]=15.85 ; p=.0164 ;{ }^{*}\right.$ indicates significance at an alpha level of 0.05$)$. The serum cortisol response for AMPH-treated and saline-treated monkeys across time under anesthesia are shown in Figure 1C. Both groups showed a significant increase in serum cortisol as the time postinduction of anesthesia increased (effect of time: $\mathrm{F}[1,7]=4.853 ; p=.0059 ;{ }^{*}$ indicates significance at an alpha level of 0.05 ).

$(\mathrm{F}[1,8]=1.869 ; p=.1366)$. For the third part of the doseresponse curve, the midrange dose, doses were adjusted between 0.4 and $0.46 \mathrm{mg} / \mathrm{kg}$ for each animal based on their responses to the 0.1 and $0.8 \mathrm{mg} / \mathrm{kg}$ AMPH challenges (see Methods section). Administration of 0.46 $\mathrm{mg} / \mathrm{kg}$ AMPH did not produce higher serum AMPH concentrations that did administration of $0.4 \mathrm{mg} / \mathrm{kg}$ $\mathrm{AMPH}$. For the adjusted midrange dose (see Figure $1 \mathrm{~A})$, the time postinjection was again significant as was the sex $\times$ time interaction (effect of time: $\mathrm{F}[1,5]=7.52 ; p=$
.0036 ; sex $\times$ time: $\mathrm{F}[1,5]=8.258 ; p=.0025)$, but there was no main effect of $\operatorname{sex}(\mathrm{F}[1,2]=0.379 ; p=.6009)$.

\section{Serum Concentrations of Prolactin and Cortisol}

As shown in Figure 1B, females had significantly higher basal serum PRL concentrations than did males independent of stage of menstrual cycle $(\mathrm{F}[1,4]=15.85 ; p=$ .0164). Both males and females, however, showed sig- 
nificant decreases in serum PRL concentrations in response to acute AMPH challenge $(\mathrm{F}[1,4]=2.98 ; p=$ $.0513)$. For example, in response to the 0.4 to $0.46 \mathrm{mg} /$ $\mathrm{kg}$ AMPH injection, female serum PRL concentrations decreased from a mean of $64.333 \mathrm{ng} / \mathrm{ml}$ at baseline to $15 \mathrm{ng} / \mathrm{ml}$ at $180 \mathrm{~min}$ postinjection, and male concentrations decreased from 10.667 to $4.667 \mathrm{ng} / \mathrm{ml}$ across the same time period (data not shown).

Serum cortisol concentrations increased with time under anesthesia whether monkeys received AMPH or saline injections (see Figure 1C). There was a significant effect of time from anesthesia induction on cortisol concentrations $(\mathrm{F}[1,3]=9.812, p=.0008)$. One of the controls had abnormally high serum cortisol concentrations $(\mathrm{F}[1,3]=9.812, p=.0008)$. One of the controls had abnormally high serum cortisol concentrations at the start of the experiment, and therefore little change in serum cortisol across time.

\section{Behavioral Responses to AMPH Challenge Pre- and Postchronic AMPH Treatment}

The left side of Figures 2 to 5 present a sampling of behavioral responses to 0.4 to $0.46 \mathrm{mg} / \mathrm{kg} \mathrm{AMPH}$ challenges for male monkeys, Jag and Glas, and female monkeys, Flo and Vien, both before and after AMPH treatment. Behavioral responses to each dose administration during the chronic phase are shown for all monkeys on the right side of Figures 2 to 5. Points on chronic graphs represent the responses given during the 1st hour following injection on the last early observation taken at each dose. Male monkey Jag spent significantly more time pacing during the 1st hour following AMPH challenge postchronic treatment than he did in response to the same challenge dose prior to treatment (Figure 2A). A much lower dose of AMPH was sufficient to elicit increased pacing in Jag after treatment than during the chronic treatment phase of the experiment $(0.4 \mathrm{mg} / \mathrm{kg}$ vs. $0.9 \mathrm{mg} / \mathrm{kg}$; see Figures $2 \mathrm{~A}$ and B). As can be seen in Figure 2C, Jag also engaged in more fine-motor stereotypies in response to $\mathrm{AMPH}$ challenge after, as compared to before, chronic treatment. This behavior was not observed in response to pretreatment challenge (Figure $2 \mathrm{C}$ ) and only periodically during the 1st hour postinjection during the chronic AMPH period (Figure 2D). Jag's fine-motor stereotypy characteristically involved an elaborate sequence of adept movements of the hands and fingers (some focused in midair, some focused on the cage bars), which looked like knitting and were referred to by the investigator as "fiddle with bars." This motor pattern became more elaborate as the number of AMPH experiences increased. Figure 2E shows that Jag made significantly more responses "independent of stimuli" during the post-treatment period than he did prior to treatment in response to a $0.4 \mathrm{mg} / \mathrm{kg}$ AMPH challenge.
Again, during the chronic period (Figure 2F), only the higher AMPH doses elicited responses "independent of stimuli." These responses most often included checking, vigilance, and staring off into space. Similar to Jag, the other male monkey, Glas, showed a trend for increased motor stereotypies in response to AMPH challenge after, but not before, chronic AMPH treatment (Figure 3A). He rarely displayed this behavior during chronic AMPH treatment (Figure 3B). Following chronic AMPH treatment, monkey Glas also spent a greater percentage of time engaged in fine-motor stereotypies in response to $\mathrm{AMPH}$ challenge than he did before treatment (Figure 3C). Like Jag, Glas displayed fine-motor stereotypies variably during the 1st hour postinjection during the chronic phase (see Figure 3D). Fine-motor stereotypies shown by Glas encompassed a variety of behaviors including: toy rotation, "fiddle with squeeze mechanism," "pull squeeze mechanism," "fiddle with chain," "fiddle with fastener." Glas showed significantly more responses "independent of stimuli" in response to AMPH challenge after chronic AMPH treatment compared to his prechronic treatment challenge at the same dose (see Figure 3E). These behaviors were also increased following some of the higher AMPH doses $(0.7-0.9 \mathrm{mg} / \mathrm{kg}$ ) during the chronic phase (Figure $3 \mathrm{~F}$ ).

Figure $4 \mathrm{~A}$ shows that monkey Flo exhibited enhanced circling behavior in response to a $0.4 \mathrm{mg} / \mathrm{kg}$ AMPH challenge after, but not before, chronic treatment. Circling behavior for monkey Flo was suppressed at the low doses and exacerbated at the high doses of AMPH during the chronic drug period (Figure 4B). After treatment, Flo also spent more time engaged in static posturing in response to post-treatment $\mathrm{AMPH}$ challenges (from day 49 on) than she did in response to her pretreatment AMPH challenge. The static posture assumed by monkey Flo after AMPH injection consisted of sitting at the front of her cage with her chest pressed flush against the bars and her arms extended toward the top of the cage with her head tilted while staring off into space. In this animal, static posturing became a predominant behavior in response to $\mathrm{AMPH}$ challenge after the chronic phase of the experiment. During the chronic phase (Figure 4D), her static posture, two arm stretch, was only displayed occasionally for very brief intervals in response to $1.0 \mathrm{mg} / \mathrm{kg}$ AMPH. As the postwithdrawal time increased, AMPH challenge induced Flo to spend a greater percentage of time engaged in responses "independent of stimuli" in response to acute AMPH challenge relative to her pretreatment challenge (Figure 4E). This behavior most often consisted of staring off into space. During the chronic phase of the experiment, responses "independent of stimuli" were increased in response to the midrange AMPH doses $(0.4-0.6 \mathrm{mg} / \mathrm{kg})$ and, to a slight extent, in response to the highest dose $(1.0 \mathrm{mg} / \mathrm{kg})$ (see Figure $4 \mathrm{~F}$ ). Notably, static posturing and responses "in- 

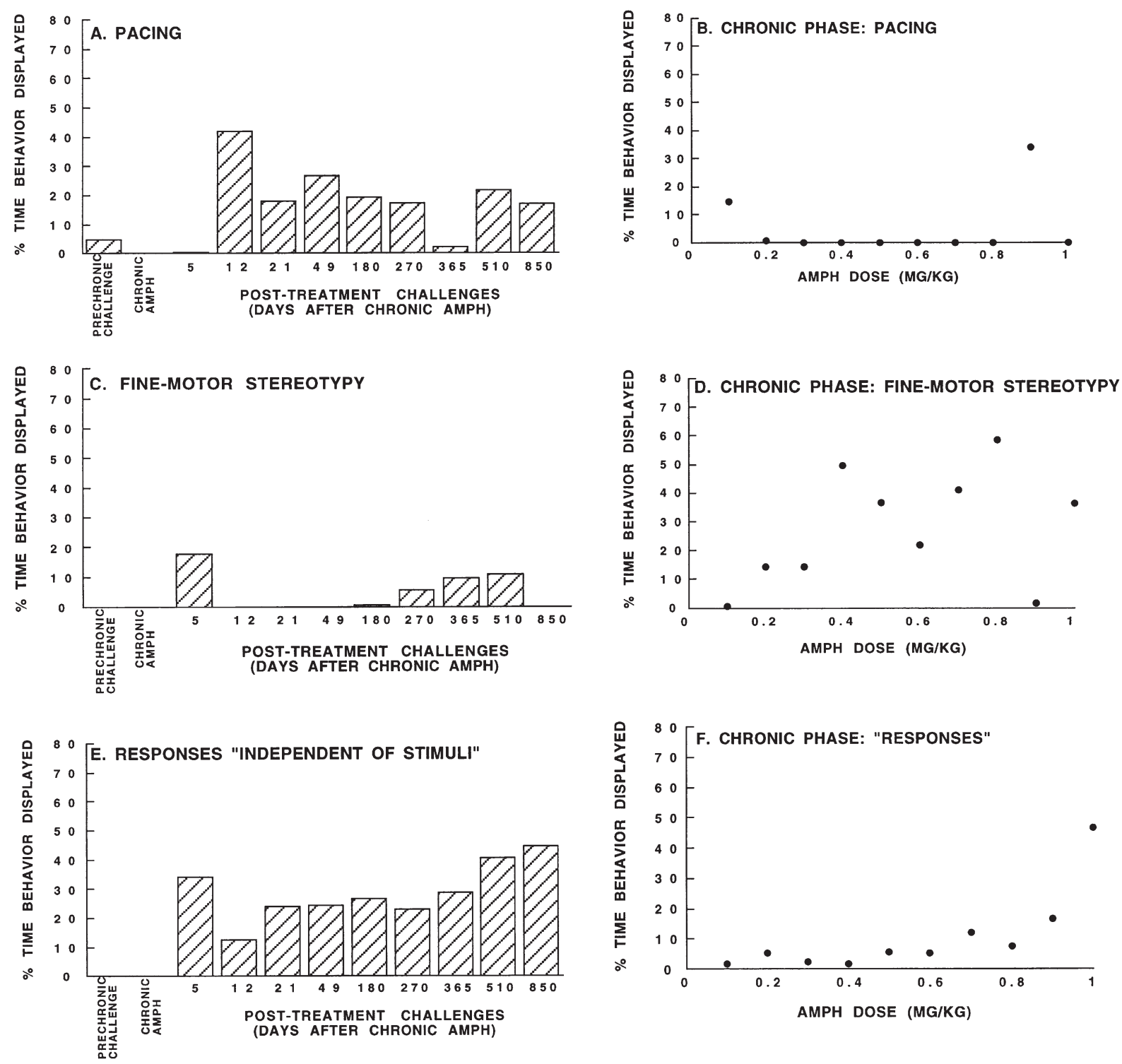

Figure 2. Panels A to F indicate the percentage of the time observed in which Jag engaged in three behaviors (pacing, finemotor stereotypy, responses "independent of stimuli") in response to AMPH injection before and after chronic AMPH treatment (A, C, E), and, across different doses during the chronic phase (B, D, F). Graphs reflect the percentage of time a given behavior was displayed during the 1st hour following AMPH injection. For most post-treatment challenges (panel A), Jag showed increased pacing relative to his pretreatment challenge. Pacing was also increased for Jag following the $0.9 \mathrm{mg} / \mathrm{kg}$ $\mathrm{AMPH}$ dose during the chronic phase of the experiment (panel B). Chronic phase data indicate the response by Jag to each dose on the morning of the last day at each AMPH dose. In response to post-treatment AMPH challenges (panel C), Jag showed fine-motor stereotypies that were not displayed in response to the same challenge dose pretreatment. He also tended to exhibit his fine-motor stereotypy, "fiddle with bars" variably following different doses during the chronic phase of the experiment (panel D). Notably, this behavior was shown by Jag for a significant percentage of time during the 1st hour following injection of $1.0 \mathrm{mg} / \mathrm{kg}$. As seen in panel E, monkey Jag spent a significant percentage of his time engaged in responses "independent of stimuli" after chronic drug treatment as opposed to predrug treatment in response to an AMPH challenge $(0.4 \mathrm{mg} / \mathrm{kg})$. Responses "independent of stimuli" were also significantly augmented at the highest dose of AMPH $(1.0 \mathrm{mg} / \mathrm{kg})$ during the chronic phase for Jag (panel F). Note: The last two post-challenge days, 510 and 850 , refer to an approximate day of challenge.

dependent of stimuli," which were often exhibited simultaneously, became pronounced responses to acute AMPH challenge for the first time on day 49 of withdrawal from chronic treatment.
The other female monkey, Vien, also showed enhanced behavioral responses to AMPH challenge following chronic treatment. Like Flo and Jag, Vien exhibited increased motor stereotypy (pacing; Figure 5A) in 

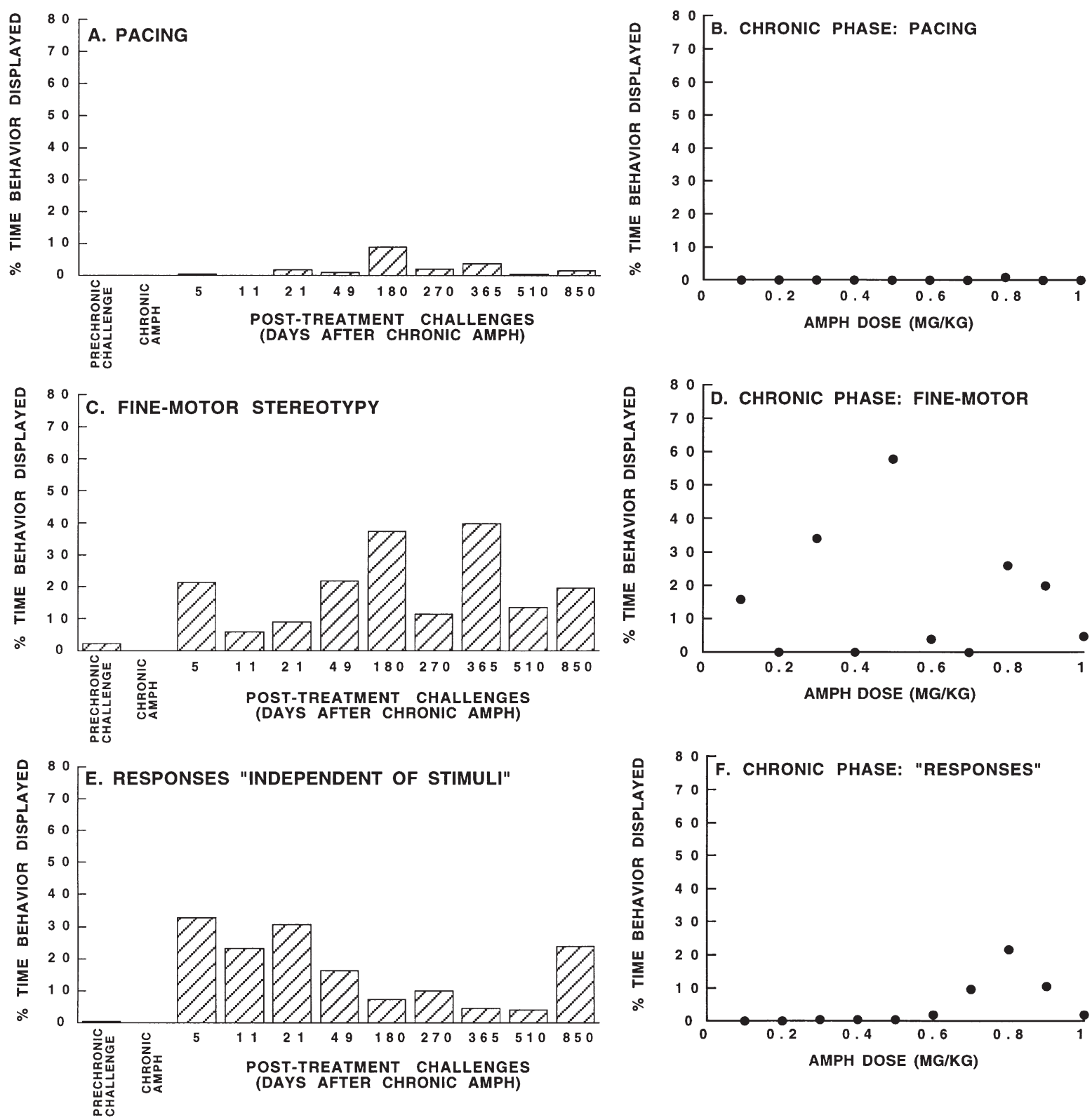

Figure 3. Panels A, C, and E show the percentage of time observed that monkey Glas engaged in pacing, fine-motor stereotypy, and responses "independent of stimuli", respectively, in response to acute AMPH challenge prior to and following chronic AMPH treatment. Similar to his baseline behavioral profile (Table 3), Gals also spent little time pacing in response to acute challenge or during chronic AMPH treatment (A and B). However, like the other monkeys, panel A does show that there was a slight increase in Glas's pacing in response to AMPH challenge after as compared to prechronic treatment. Like Jag, Glas also spent a significantly greater percentage of his time engaging in fine-motor stereotypies in responses to posttreatment as opposed to pretreatment acute AMPH challenge (panel C). Again similar to Jag's response, Glas spent a variable percentage of time engaged in fine-motor stereotypies in response to different AMPH doses during the chronic phase (panel D). Responses "independent of stimuli" were elicited by lower AMPH challenge doses $(0.45 \mathrm{mg} / \mathrm{kg}$, panel E) than during chronic treatment $(0.7$ to $0.9 \mathrm{mg} / \mathrm{kg}$, panel F).

response to acute challenge after, but not before, chronic treatment. On the other hand, she rarely paced in response to $\mathrm{AMPH}$ injection during the chronic phase (see Figure 5B). Vien, like the other female Flo, spent more time engaged in static posturing in response to acute AMPH challenge as the time postwithdrawal increased and as compared to her pretreatment response for this behavior (Figure 5C). Vien's static postures were sometimes similar to those exhibited by Flo; that is, she also sat for extended periods at the front of 

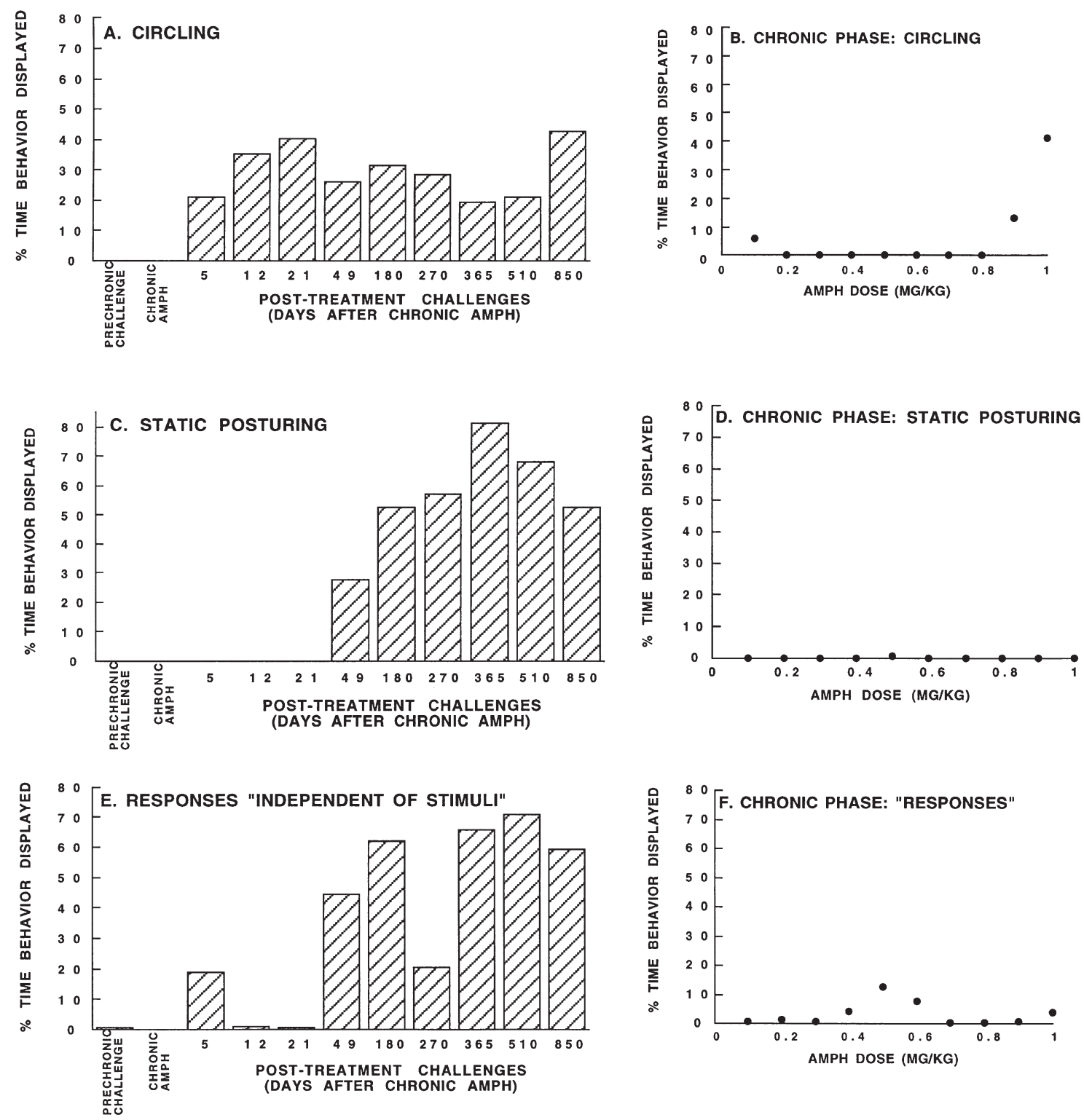

Figure 4. Figures $4 \mathrm{~A}$ to $\mathrm{F}$ indicate the mean percentage time spent by female monkey Flo engaged in circling (A and B), static posturing (C and D), and responses "independent of stimuli" (E and F) during the 1st hour after AMPH injection. The left panels contain behavioral data for acute AMPH challenges $(0.4 \mathrm{mg} / \mathrm{kg})$ before and following chronic AMPH treatment. Data in the right panels pertain to the chronic phase of the experiment. Similar to monkey Jag, Flo showed a higher incidence of circling behavior in response to AMPH challenges post-treatment as compared to the same dose challenge prior to chronic $\mathrm{AMPH}$ treatment (A). As seen in panel B, circling was also displayed by Flo in response to the higher doses during the chronic phase of the experiment. Figure $4 \mathrm{C}$ shows that Flo spent a significantly greater percentage of her time engaged in static posturing in response to acute AMPH challenge following post-treatment challenges from day 49 on than she did prior to this time. Although it is not detectable in Figure 4D, static posturing was interjected by Flo for brief periods (10 to $15 \mathrm{~s}$ ) during the chronic phase in response to $1.0 \mathrm{mg} / \mathrm{kg}$ AMPH. Panel E illustrates the significant increases in responses "independent of stimuli" for Flo in response to post-treatment as compared to pretreatment AMPH challenge. Responses "independent of stimuli" were displayed variably across doses during the chronic phase by Flo (F). Notably these behaviors were often displayed in conjunction with static posturing in response to post-treatment challenges.

the cage with one arm extended over her head and her chest pressed against the cage bars. However, Vien also displayed a static posture that was more withdrawn and involved cowering in the back corner of her cage clinging to bars with two hands and one foot. Vien spent a greater percentage of time engaged in static posturing in response to $0.9 \mathrm{mg} / \mathrm{kg}$ AMPH than she did in response to the other doses during chronic treatment (see 

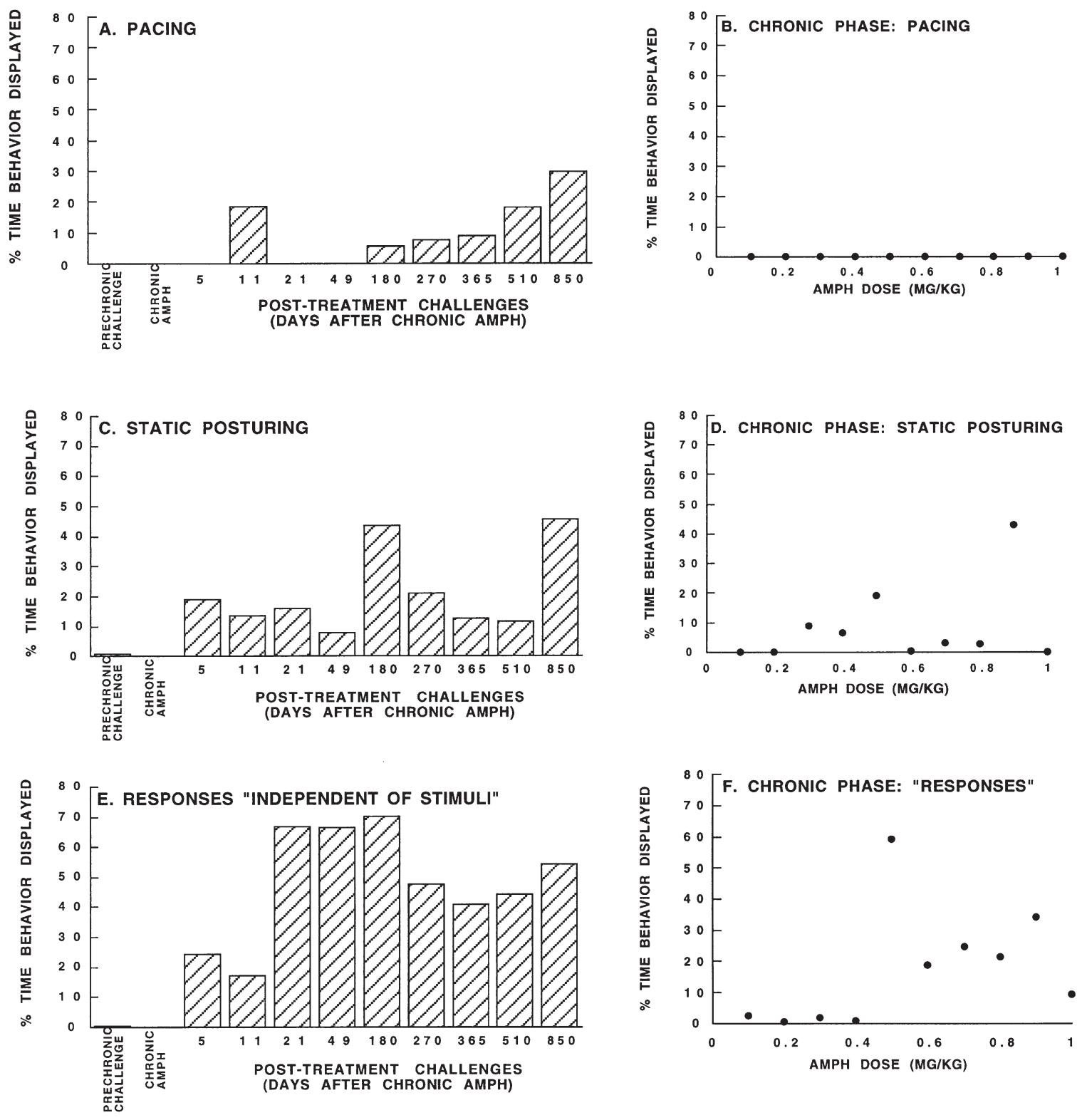

Figure 5. Figure 5 shows the percentage time spent by female monkey Vien engaged in pacing, static posturing, and responses "independent of stimuli" during the 1st hour following AMPH injection. Figures A, C, an E show these behaviors in response to acute AMPH challenge before and after chronic AMPH treatment, and Figures B, D, and F show the incidence of each behavior across doses during the chronic phase. As can be seen by comparing Figures A and B, pacing behavior was only displayed by monkey Vien in response to AMPH injection following chronic treatment. Vien spent significantly more time engaged in static posturing in response to $0.46 \mathrm{mg} / \mathrm{kg}$ AMPH after chronic treatment than she did prior to treatment (C). Figure D shows that this behavior was expressed for a longer duration in response to $0.9 \mathrm{mg} / \mathrm{kg} \mathrm{AMPH}$ than it was in response to the other AMPH doses during chronic AMPH treatment. Like the other two behaviors, responses "independent of stimuli" were a prominent behavioral response exhibited by Vien in response to AMPH challenge only after chronic treatment. Vien also spent a significant percentage of time displaying these behaviors during the chronic phase of the experiment in response to the higher AMPH doses $(0.5$ to $1.0 \mathrm{mg} / \mathrm{kg}$; see $5 \mathrm{~F})$.

Figure 5D). Again, similar to the other AMPH-treated monkeys. Vien displayed significantly more responses "independent of stimuli" including checking, tracking nonapparent stimuli, and staring off into space to AMPH challenge after chronic treatment than she did prior to chronic treatment (Figure 5E). During chronic treatment, responses "independent of stimuli" were more often displayed by this monkey in response to higher, as compared to lower, doses of AMPH (see Figure $5 \mathrm{~F})$. 


\section{Time Course and Progression of Enhanced Behavioral Responses to AMPH Challenge}

Table 4 highlights the time course of responses "independent of stimuli" in response to either acute AMPH challenge (Jag and Vien) or saline challenge (Mad and Kram). For each monkey, data shown indicate the percentage time displaying responses "independent of stimuli" in response to three acute injections; pretreatment, 21 days post-treatment, and 9 months post-treatment (Kram did not receive his post-treatment challenges at the same time as the other monkeys because of his relocation to another monkey room). Neither Jag nor Vien displayed significant responses "independent of stimuli" in response to acute AMPH challenge before chronic treatment. In contrast, following treatment, both monkeys showed a significant increase in the percentage of time engaged in this category of behavior in response to AMPH challenge. Remarkably, in response to AMPH challenge at 21 days and 9 months post-treatment, Jag and Vien showed persistence of responses "independent of stimuli" through 6 hours and, in most cases, through 72 hours postinjection. In contrast to the AMPH-treated monkeys, saline challenge almost never induced responses "independent of stimuli" in the two control monkeys, Mad and Kram.

\section{Behavioral Changes Off-Drug After Chronic AMPH Treatment}

In contrast to their enhanced responses to AMPH challenge after chronic treatment, most of the experimental monkeys showed significant decreases in the time spent engaged in motor stereotypies in the interim between challenges. For example, monkey Jag (Figure 6A) spent significantly less time pacing immediately following withdrawal from $\mathrm{AMPH}$, between 3 and 9 months postwithdrawal, and, subsequently out to 15 months postwithdrawal as compared to his prechronic treatment baseline behavior $(\mathrm{F}[3,82]=23.543 ; p=.0001)$. Monkey Vien also spent significantly less time pacing across all of her postchronic AMPH observations as compared to her pretreatment baseline samples $(\mathrm{F}[3,82]=$ $8.285 ; p=.0001{ }^{*}$ indicates significant at $95 \%$ via Fischer PLSD and Scheffe F-test; Figure 6B). Flo showed a later onset of behavioral suppression after chronic AMPH treatment, exhibiting diminished circling only between 3 and 9 months postchronic AMPH treatment as compared to her baseline values $(\mathrm{F}[3,73]=5.263 ; p=$ $.0024 ;{ }^{*}$ indicates significant at $95 \%$ via Fischer PLSD and Scheffe F-test; Figure 6C). The other male monkey, Glas, (see Figure 6D) displayed only minimal motor stereotypies (pacing, one arm twirling, and somersaulting) before chronic AMPH administration, and, therefore, did not show a significant decrease in these behaviors in the months following withdrawal from $\mathrm{AMPH}$ $(\mathrm{F}[3,78]=1.391 ; p=.2517)$.

Different from motor stereotypies, certain aberrant behaviors; for example, responses "independent of stimuli" continued to be expressed by some AMPHtreated monkeys even in the interim between drug challenges. For example, Vien showed high levels of responses "independent of stimuli" including: tracking nonapparent stimuli, cowering, and staring off into space. She often spent as much as $30 \%$ of her time observed engaging in such responses. The other AMPHtreated monkeys also showed an increased incidence of responses "independent of stimuli" after chronic drug treatment in the absence of additional drug challenges. In this study, after chronic AMPH administration, both male monkeys developed buccolingual dyskinesias, which were exacerbated by acute challenge and some-

Table 4. Timecourse of Responses "Independent of Stimuli" After Acute AMPH or Saline Challenge

Hours Post-injection

\begin{tabular}{|c|c|c|c|c|c|c|c|c|}
\hline \multirow{2}{*}{$\begin{array}{l}\text { Monkey } \\
\text { Name }\end{array}$} & \multirow{2}{*}{$\begin{array}{c}\text { Challenge } \\
\text { Time }\end{array}$} & \multicolumn{7}{|c|}{ (Percentage Time Displaying Responses "Independent of Stimuli") } \\
\hline & & Hour 1 & Hour 2 & Hour 3 & Hour 6 & Hour 24 & Hour 48 & Hour 72 \\
\hline \multirow[t]{3}{*}{ JAG } & Pretreatment & 00.13 & 00.58 & - & 01.50 & - & - & - \\
\hline & Post-treatment (21 d) & 24.10 & 61.10 & 95.12 & 29.00 & 00.00 & 00.00 & 11.00 \\
\hline & Post-treatment ( $9 \mathrm{mo})$ & 22.91 & 23.00 & 41.19 & 63.70 & 24.70 & 05.15 & 00.00 \\
\hline \multirow[t]{3}{*}{ VIEN } & Pretreatment & 00.45 & 00.88 & - & 00.02 & 00.00 & 00.09 & - \\
\hline & Post-treatment ( $21 \mathrm{~d})$ & 66.81 & 35.40 & - & 40.45 & 15.94 & 09.29 & 14.00 \\
\hline & Post-treatment (9 mo) & 47.60 & 56.00 & 73.6 & 04.60 & 08.67 & 20.49 & 03.30 \\
\hline \multirow[t]{3}{*}{ MAD } & Pretreatment & 00.00 & - & - & 00.00 & - & - & - \\
\hline & Post-treatment (21 d) & 00.00 & - & - & 00.00 & - & - & - \\
\hline & Post-treatment (9 mo) & 00.00 & - & - & 00.00 & - & - & 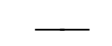 \\
\hline \multirow[t]{3}{*}{ KRAM } & Pretreatment & 00.00 & - & - & 00.00 & - & - & 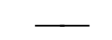 \\
\hline & Post-treatment ${ }^{a}$ & 00.00 & - & - & 00.00 & - & - & - \\
\hline & Post-treatment ${ }^{a}$ & 00.14 & - & - & 00.00 & - & - & - \\
\hline
\end{tabular}

${ }^{a}$ Kram's post-treatment challanges varied, because he was transferred to another facility after the chronic period. 

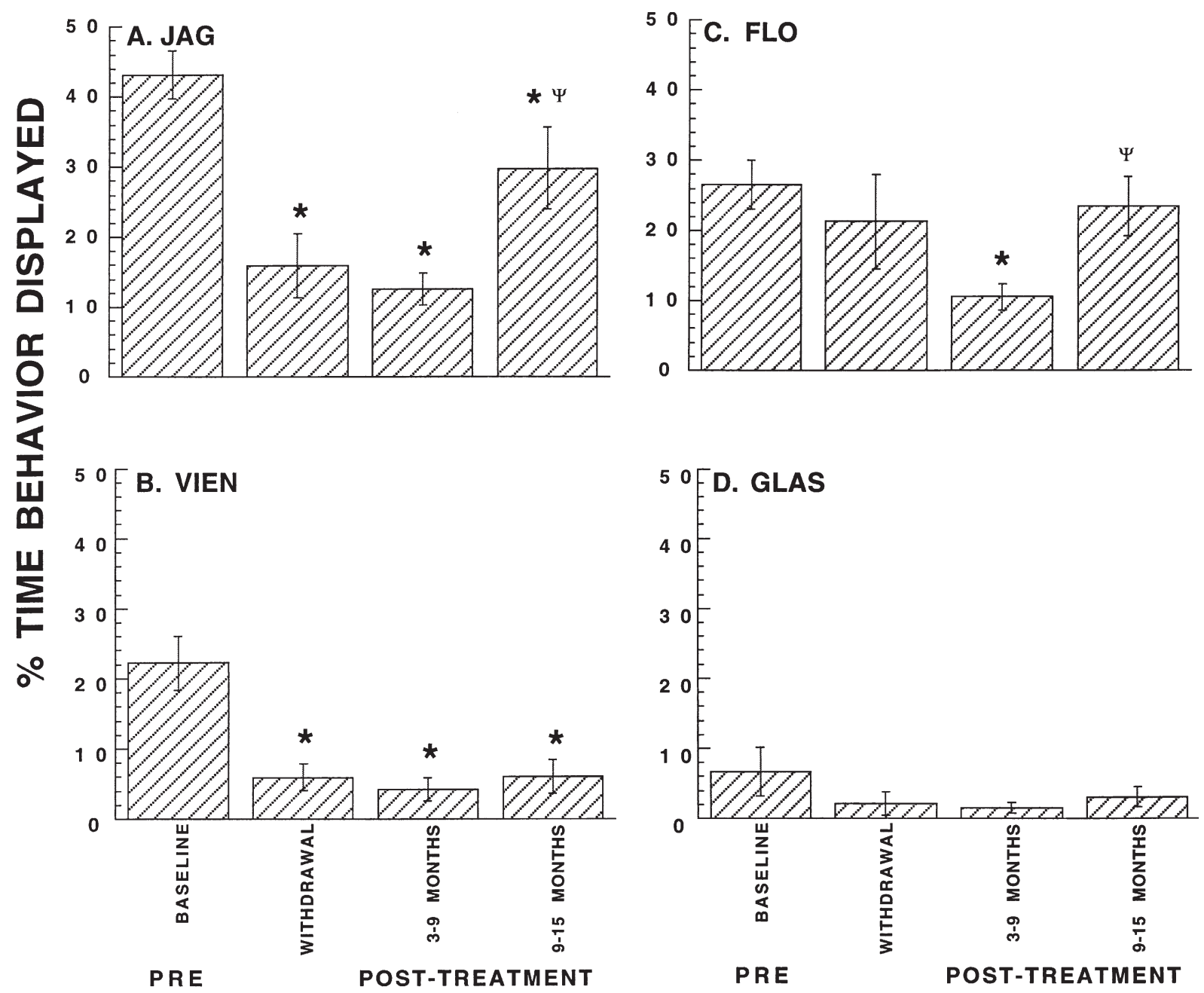

Figure 6. Figure 6 shows the mean ( \pm SEM) percent time the four AMPH-treated monkeys displayed motor stereotypies off drug at different time points before and after chronic AMPH. Behavioral observations of motor stereotypies off drug were collected from four different time points: baseline (pretreatment), initial withdrawal from chronic AMPH, 3 to 9 months post-treatment, 9 to 15 months post-treatment. Monkey Jag, shown in panel A, spent significantly less time pacing immediately following withdrawal from AMPH, across 3 to 9 months postwithdrawal, and from 9 to 15 months postwithdrawal as compared to his baseline for this behavior prior to chronic AMPH $(\mathrm{F}[3,82]=23.543 ; p=.0001)$. Monkey Vien $(6 \mathrm{~B})$ also spent significantly less time pacing during all post-treatment time points tested compared to her baseline pacing behavior $(\mathrm{F}[3,82]$ $=8.285 ; p=.0001)$. In contrast, monkey Flo $(6 \mathrm{C})$ only showed a significant decrease in her circling behavior during the period between 3 to 9 months post-treatment $(\mathrm{F}[3,73]=5.263 ; p=.0024)$. Monkey Glas (shown in $6 \mathrm{D})$ showed the same general behavioral pattern as did the other AMPH-treated monkeys, but none of the comparisons of data across different time points for this monkey were significant $(F[3,78]=1.391 ; p=.2517)$. All single * indicates significance at 95\% via Fischer PLSD and Scheffe F-test. Jag and Flo showed recovery of pacing and circling, respectively, during 9 and 15 months after chronic AMPH treatment $(\psi)$.

times persisted for several days. One male, Jag, also displayed self-biting after chronic drug treatment.

The behavioral response of each monkey to the investigator was recorded on a daily basis. During chronic AMPH treatment, and in response to acute AMPH challenges postchronic treatment, normally aggressive monkeys (Jag and Vien) evidenced an increased incidence of submissive behaviors including presentation, lipsmacking, and reaching out to the investigator.

\section{Saline-Treated Animals}

There was very little variance in behaviors expressed by the two male control monkeys either during baseline observations or in response to saline challenge (see Tables 3 and 4). Neither of the control monkeys showed significant levels of any behaviors that were found to be enhanced in the AMPH-treated monkeys: for example, responses "independent of stimuli" (Table 4), fine-motor stereotypies, parasitotic-like grooming, static posturing, or buccolingual dyskinesias (data not shown). 


\section{Four-Week AMPH Pilot Study}

The monkey subjected to the 4-week escalating lowdose AMPH regimen also displayed enhanced behavioral responses to low-dose AMPH challenge following chronic treatment as compared to her pretreatment challenge. Her enhanced behavioral responses were similar to those described above for the 12-week-treated monkeys. She continued to display enhanced responses to acute AMPH Challenge through her final challenge, which was given at approximately 3 months postchronic AMPH treatment and 1 week prior to sacrifice. TH and DAT immunoreactivity in the striatum did not reveal any apparent differences between the AMPH-treated monkey and age-matched control (Figures 7A-D).

\section{DISCUSSION}

The present study is the first to report on the behavioral consequences of repeated, intermittent, escalating lowdose AMPH exposure in the nonhuman primate and to determine the period of time over which these consequences last. The major findings of this longitudinal study on repeated low-dose AMPH exposure in rhesus monkeys are several fold. First, this chronic treatment regimen induces enhanced behavioral responses to acute AMPH challenge as long as 28 months postwithdrawal. Second, the behaviors elicited by acute lowdose AMPH challenge resembled behavioral responses that have previously been described only for chronic and/or high-dose AMPH treatment in monkeys. Third, aberrant behavioral responses induced by acute lowdose AMPH challenge tended to persist for several days following the challenge in monkeys pretreated with chronic AMPH. Fourth, chronically AMPH-treated monkeys showed aberrant behavioral responses in the absence of additional drug challenges. Finally, as extensively documented in rodents, our behavioral and serum data indicate that there may be sex differences in the biochemical as well as in the behavioral response to $\mathrm{AMPH}$ in rhesus monkeys.

\section{Behavioral Consequences of Repeated AMPH Exposure in Rhesus Monkeys}

Findings from the present study indicate that monkeys previously exposed to intermittent, repeated, escalating low-doses of AMPH display enhanced behavioral responses to subsequent acute low-dose AMPH challenges. Similar to findings from rodent studies, monkeys in the present study showed enhanced behavioral responses during chronic treatment and in response to acute low-dose AMPH challenges shortly after withdrawal as compared to their prechronic AMPH challenge, and these enhanced responses to acute $\mathrm{AMPH}$ challenge seemed to be relatively permanent (e.g., Bickerdike and Abercrombie 1997; Paulson et al. 1991).

The monkeys in this study also displayed behavioral depression following withdrawal from chronic AMPH treatment. Previous studies (e.g., Utera 1966) have shown that the behavioral depression evident following withdrawal tends to be transient in nature, with the length of the depression being positively correlated with the duration of chronic treatment. In contrast, although the present study in nonhuman primates is based on a small $n$, findings indicate considerable individual variability in recovery from behavioral depression, as is likely to be the case for humans. For example, while one monkey's (Flo) circling behavior returned to baseline by 9 months postchronic AMPH treatment, others (Jag and Vien) were still showing significantly less pacing behavior between 9 and 15 months post-treatment than they did before chronic AMPH treatment. One difference between rats and monkeys exposed to repeated AMPH is that rats show maximal behavior enhancement at 1 month postwithdrawal; whereas, behavioral responses to AMPH challenge in monkeys seem to become more "intense" as the time postwithdrawal increases.

One possible interpretation of our findings on repeated, intermittent low-dose AMPH exposure in monkeys is that they developed behavioral sensitization to AMPH. Behavioral sensitization refers to the enhanced behavioral response to an acute low-dose drug challenge shown by individuals having previous intermittent experiences with that drug or a similar agent (including stressors) as compared either to their own predrug baseline or to drug-naive controls (for reviews see Robinson and Becker 1986; Kalivas and Stewart 1991). The phenomenon of behavioral sensitization to psychomotor stimulants, such as AMPH and cocaine, has been extensively studied and well documented in rodents, but little is known about sensitization in nonhuman and human primates. The findings of enhanced behavioral responses to acute AMPH challenge out to 28 months post-treatment could be the first definitive evidence of long-lasting behavioral sensitization to AMPH in the nonhuman primate pending postmortem findings.

Another possible interpretation of the alterations in behavior observed after repeated, intermittent exposure to AMPH in rhesus monkeys might be neurotoxicity. At present, little data are available on the long-term neurochemical and biochemical consequences of repeated low-dose AMPH exposure in nonhuman primates or humans. Findings from one in vivo imaging study in humans suggests that neurotoxicity is not present in the striatum of repeated AMPH abusers (Wilson et al. 1996). Nevertheless, neurotoxicity cannot be ruled out as an explanation for some of the persistent behavioral abnormalities in the AMPH-treated monkeys, including the long-lasting behavioral depression that was observed in some of the monkeys. Several recent PET 
A

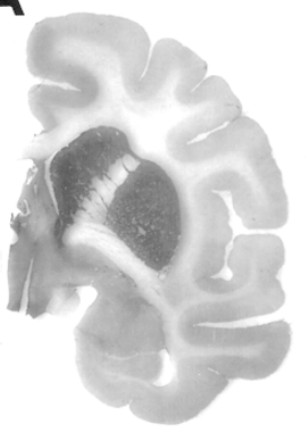

B

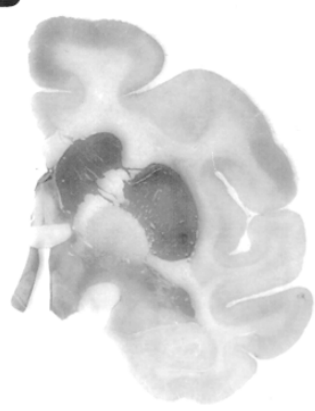

C

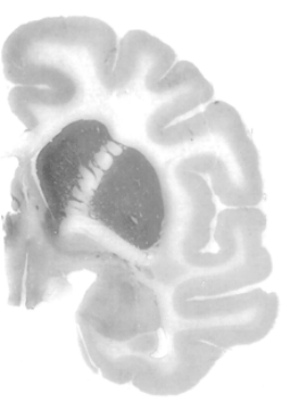

D

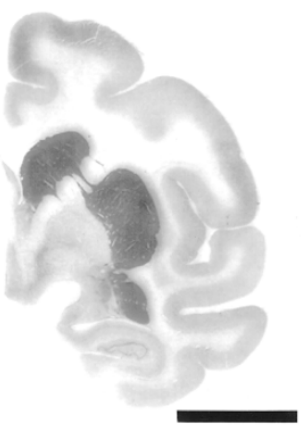

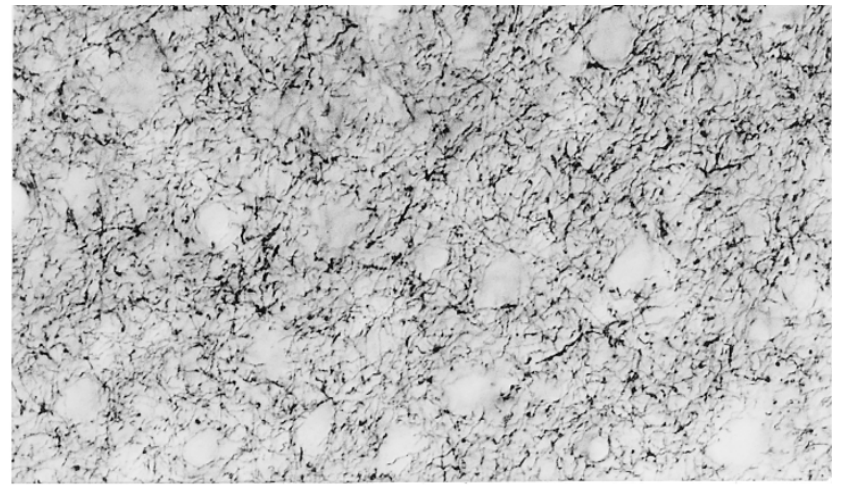
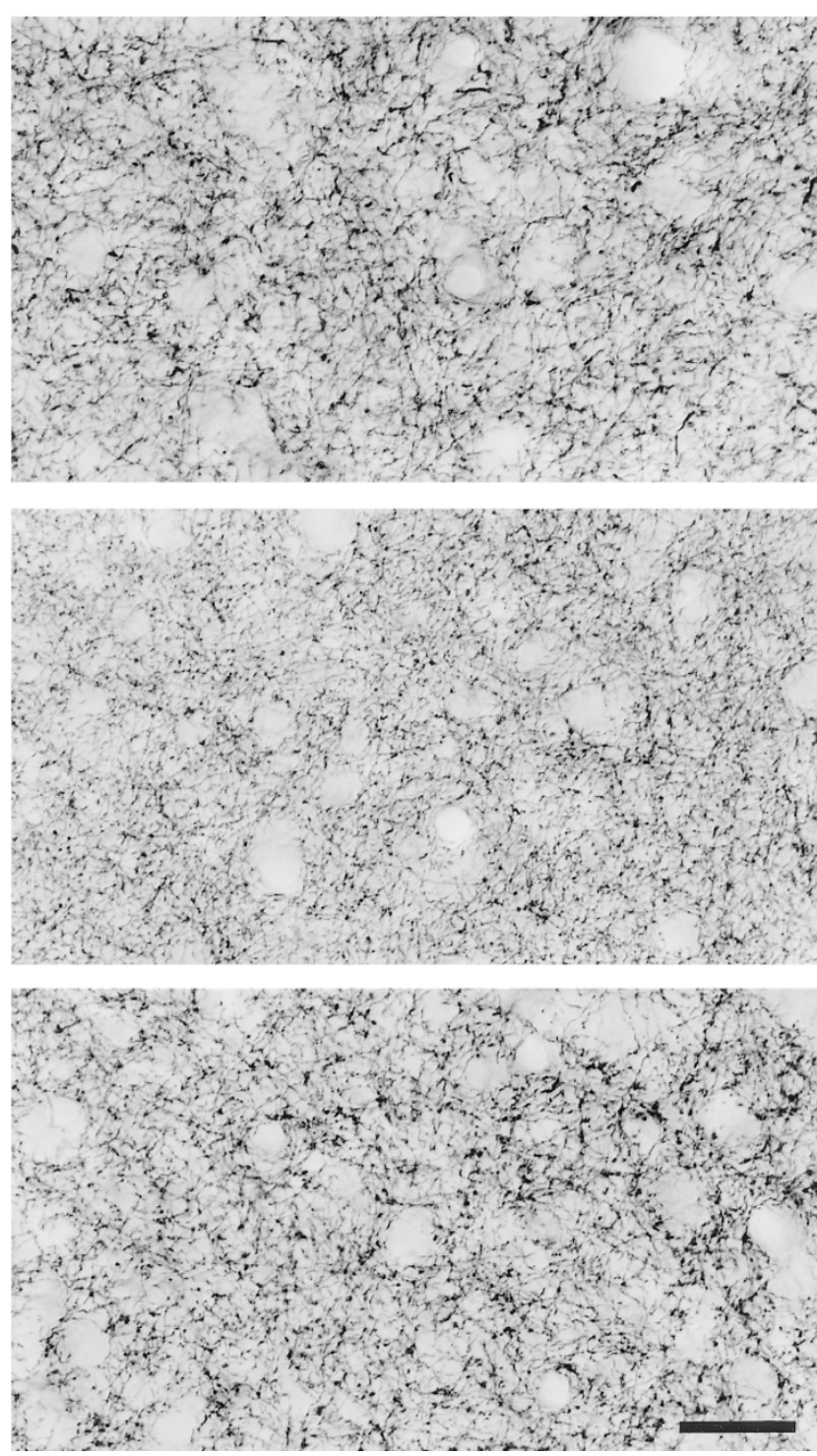

Figure 7. Markers of catecholamine synthesis and dopamine transport, $\mathrm{TH}$ (A and $\mathrm{B}$ ) and DAT (C and D), immunoreactivities are shown for an age-matched control (A and $\mathrm{C}$ ) and a 4-week AMPH-treated monkey (B and D). Figures on the left side are low-magnification (scale bar $=1 \mathrm{~cm}$ ) and those on the right are high-magnification photomicrographs (scale bar $=10 \mu \mathrm{m})$ of the caudate nucleus of the respective sections on the left side. No significant difference in $\mathrm{TH}$ immunoreactivity in the caudate nucleus of the control and AMPH-treated monkeys could be found (compare A [control] and B [AMPHtreated]). There were also no observable differences in the intensity of DAT immunoreactivity in the caudate of the control and AMPH-treated monkeys, C and $\mathrm{D}$, respectively. studies in nonhuman primates have found that a longlasting reversible depression of the striatal dopamine system exists in both monkeys and baboons that have received several injections of $\mathrm{AMPH}$ at doses only slightly higher than those used in the present study (Melega et al. 1997; Villemagne et al. 1998). In fact, this type of neuronal depression, sometimes referred to as reversible neurotoxicity, might help to explain the persistent behavioral effects that were observed over several days following a low-dose challenge in the AMPHtreated monkeys in the present study.

However, other pieces of preliminary data from ongoing studies in our laboratory indicate that striatal neurotoxicity, if it exists at all, may not be pronounced 
in our AMPH-treated animals and, therefore, not a full explanation of the behavioral consequences of repeated low-dose AMPH exposure in the present study. First, histological examination of TH and DAT immunoreactivity in the striatum has not so far revealed any significant differences between the 4-week AMPH-treated monkey and an age-matched control. Although there was evidence for increased dopamine turnover in the prefrontal cortex, the AMPH-treated monkey had normal tissue concentrations of dopamine in both the striatum and prefrontal cortex (unpublished observations, Castner et al.). Because several parameters of striatal and cortical dopamine function were not found to be compromised in the 4-week AMPH-treated monkey, and this monkey was subjected to the same doses of AMPH as the 12-week monkeys (albeit the AMPH doses were escalated more rapidly in the former), we suspect that the histological data obtained from the 4-week monkey implies that our intermittent low-dose AMPH treatment regimen may induce neural protection rather than degeneration of the dopamine system. Second, we have conducted a single-photon emission computed tomography (SPECT) imaging study to see if we could measure potentiation of AMPH-stimulated dopamine release by examining AMPH's ability to induce dopamine release and displace, iodine-123 iodobenzamide, [I123]-IBZM bound to striatal D2 dopamine receptors before and after 6 weeks of AMPH treatment (same AMPH doses used in the present experiment, but more rapid escalation). Results from four sensitized monkeys indicate that there are slight decreases in the percentage displacement at 1 month postchronic AMPH treatment as compared to pretreatment (Castner et al., in preparation). Taken together, these findings suggest that our escalating, intermittent, low-dose AMPH treatment regimen does not seem to result in frank striatal neurotoxicity. However, because we have not examined animals in the present study, striatal neurotoxicity or toxicity to other brain regions cannot be ruled out in this group of animals. However, it is important to point out that evidence of neural damage in these monkeys would not invalidate their potential value as animal models of psychosis, because our aim is to determine how closely their potential pathology resembles that which has already been described in postmortem studies of schizophrenic brains (Selemon et al. 1995, 1998; Benes et al. 1991). Indeed, the ultimate goal of this work is to produce an animal in whom cortical pathology is identical to that observed in schizophrenics.

\section{Persistent Behavioral Responses in the Absence of Additional Drug Challenge}

In some respects, the extent to which some monkeys show enhanced responses to AMPH challenge after chronic AMPH treatment was unexpected. Extrapolating from our serum data, the half-life of AMPH seems to be about 6 to 8 hours, similar to that in humans. AMPH's metabolic profile accounts for the finding that treated monkeys continued to exhibit significant druginduced behaviors between 6 and 8 hours postinjection. However, it does not explain the persistence of symptomatology following a single $0.4 \mathrm{mg} / \mathrm{kg}$ AMPH challenge over a period of days, when it seems unlikely that any drug would remain in the system. Therefore, it may be the case, as mentioned above for either sensitization or neurotoxicity, that persistent behavioral abnormalities may reflect long-lasting changes in the system resulting from chronic, repeated AMPH administration. In addition, or conversely, it is possible that persistence of AMPH-induced behaviors after AMPH has already been metabolized in previously AMPH-treated animals could be explained by long-lasting system changes in response to an acute challenge, similar to those changes described in imaging studies in nonhuman primates (Melega et al. 1997; Villemagne et al. 1998). On the other hand, it could be the case that even extremely low concentrations of AMPH that might be present in the system in the days following the challenge are sufficient to produce the behavioral manifestations of the drug (e.g., Chuang et al. 1981). Another possible interpretation of the data is that the aberrant behaviors that manifest over a period of days after repeated AMPH treatment could reflect conditioned responses to the injection (Jodogne et al. 1994; Cabib et al. 1996; Antelman 1994; Antelman and Caggiula 1996). This statement does not imply that a single conditioned stimulus produces the behaviors, but that the entire context of the experimental days surrounding the injection contributes to the continued display of behaviors. In fact, there is considerable data in rodents that indicate that the conditions present during the induction of behavioral sensitization may affect expression of the sensitized response (Badiani et al. 1997; Badiani et al. 1995a,b; Post et al. 1992; Stewart 1992). In the present study, some AMPHtreated monkeys exhibited AMPH-like behaviors even in response to a saline challenge (personal observations). Further study is needed to explore these possibilities.

\section{Putative Sex Differences in the Behavioral Consequences of Repeated AMPH Administration in Rhesus Monkeys}

In rodents, it has been shown that intact females show a greater behavioral response to AMPH than do intact males (Beatty and Holzer 1978; Savageau and Beatty 1981; Robinson et al. 1982a; Becker et al. 1982; Robinson et al. 1982b). In the same vein, several observations in the present study are suggestive of sex differences in behavioral responses to AMPH in nonhuman primates. 
For example, one such difference that emerged in this study was static posturing. After chronic AMPH treatment, both females spent extended periods of time in static postures in response to AMPH challenges, whereas, neither of the males showed static posturing as a response to AMPH challenge. Conversely, AMPHtreated male monkeys in this study continued to engage in movement around the homecage as well as to show higher levels of fine-motor stereotypies in response to AMPH challenge than did females following chronic treatment. In response to AMPH treatment in the present study, both males and females showed increased submissive responses. However, the two sexes showed this increase differently; that is, males lipsmacked, the females presented. Based on data from this study, as well as data from other monkeys exposed to repeated AMPH in the lab, AMPH-induced appetite suppression seems to be more pronounced among young adult females, although some highly responsive males; for example, Jag, also showed significant appetite suppression both during chronic AMPH and in response to acute AMPH challenge post-treatment. In the rat, decreased ambulation and more focused stereotypy is considered a more "intense" response to AMPH than hyperlocomotion, based on dose-response studies (for discussion see Segal and Kuczenski, 1994). Thus, from the present findings, it might be tentatively concluded that females showed a more "intense" behavioral response to repeated AMPH treatment and subsequent AMPH challenge. However, this conclusion is highly preliminary, because one other male (in another 6-week AMPH study) has shown a response similar to that of the AMPH-treated females in this study (personal observations), and it is possible that sex differences in the behavioral response to AMPH of nonhuman primates may be masked by individual differences in AMPH responsivity. Individual differences may also help to explain the lack of pronounced sex differences in AMPH metabolism in the nonhuman primate. Recall that serum $\mathrm{AMPH}$ concentrations were obtained to determine if there were sex differences in AMPH metabolism in the nonhuman primate similar to those that have been described for rodents (e.g., Becker et al. 1982). Hepatic metabolism of AMPH is more rapid in male rats than it is in females. Thus, it is necessary to administer a slightly higher dose of $\mathrm{AMPH}$ to male rats in order to equate serum AMPH concentrations in male and female rats, and thereby, to ensure that behavioral differences reflect actual sex differences rather than metabolic differences. In the monkey, although there was a tendency for females to show higher peak serum concentrations of $\mathrm{AMPH}$, no significant sex differences were observed in serum AMPH concentrations. In fact, at the midrange challenge dose, males tended to show higher serum concentrations than females during the 2nd and 3rd hours postinjection. Because the midrange dose was used for acute challenges, it is possible that this latter finding might help to explain the different behavioral profiles observed in the two sexes.

\section{Repeated, Low-Dose AMPH Exposure in Rhesus Monkeys as a Model of Psychosis}

The longitudinal model of repeated, low-dose AMPH exposure in rhesus monkeys developed here may provide insights into the etiology of schizophrenic psychoses. It has been suggested that any valid animal model of psychosis requires several key features (Liddle et al. 1992). First, it is necessary for such a model to induce what is classically defined as positive-like symptoms including hallucinatory-like behaviors. In the present study, 28 months after chronic AMPH treatment, monkeys responded to a low-dose AMPH challenge with myriad responses "independent of stimuli," including checking, tracking or swatting at nothing in the air, and staring off into space. Possibly even more revelant to the evaluation of repeated, low-dose AMPH exposure in monkeys as an animal model of psychosis is the fact that even at 20 months postdrug treatment, some monkeys continued to show aberrant behaviors in the absence of additional pharmacological challenge. Because some of the behavioral changes induced by repeated low-dose AMPH exposure appear to be "permanent," it is possible that some of the biochemical and anatomical changes found in our AMPH-treated monkeys' brains might be similar to those found in schizophrenics. Studies are currently in progress for comparing the cortex of amphetamine-treated monkeys and schizophrenics. Second, any potential animal model of schizophrenia should induce negative-like symptoms. In the repeated, low-dose AMPH exposure model presented here, some of the behaviors observed both during the latter stages of chronic AMPH treatment as well as in response to low-dose AMPH challenge in previously treated animals could be viewed as analogous to the increase in negative symptoms observed in schizophrenic patients over time (Dollfus and Petit 1995; Kulhara and Chandiramani 1990). For example, the static postures assumed by the females in response to AMPH challenge could be considered evidence of negative-like symptomatology stemming from repeated exposure to AMPH (Liddle et al. 1992). The persistent behavioral depression shown by some animals for up to 20 months after withdrawal, in the absence of drug, could be viewed as similar in nature to the psychomotor poverty syndrome that has been described in schizophrenic patients.

Because it is relatively easy to induce both positivelike and negative-like behavioral changes with pharmacological agents such as AMPH, it seems most important that any valid animal model simulate the third and most difficult-to-treat aspect of the schizophrenic syndrome, cognitive deficits. Preliminary results from a 
test of frontal lobe function in primates, the object retrieval task, suggest that repeated exposure to AMPH in monkeys impairs performance on this task (Castner and Goldman-Rakic, in preparation). The findings for AMPH-treated monkeys on the object retrieval task are similar to those that have been shown for subchronic PCP exposure in nonhuman primates on this task (Jentsch et al. 1997). Recently, we have shown that monkeys treated for 6 weeks with escalating, intermittent low-doses of AMPH show impairments on the object retrieval task up through 6 to 7 months postchronic treatment. Some of these 6-week treated monkeys are currently undergoing testing on varied spatial delayed response to see if the frontal lobe deficit suggested by the results from the object retrieval task extends to the realm of working memory. In sum, we have shown that repeated, intermittent exposure to escalating low-doses of AMPH produces monkeys that exhibit both negative-like and positive-like symptomatology in the presence and in the absence of drug. Although our AMPH treatment regimen cannot induce schizophrenia, it can establish a chronic condition that includes long-lasting neurochemical, biochemical, and behavioral changes. Therefore, repeated exposure to low-dose AMPH in rhesus monkeys may provide a powerful paradigm for studying the role of dopamine dysregulation in the induction of psychosis and a possible etiology of schizophrenia.

\section{ACKNOWLEDGMENTS}

The authors thank Tatyana Trakht and Heather Findlay for their expert technical assistance on this project. We also thank Dr. Robert Jakab for his help with photomicrography and Dr. Leonid Krimer, as well as Dr. Jakab, for their advice on immunocytochemistry. In addition, we thank Jonathon Traupman for creating the Monkey Watcher program. This work was supported by the Stanley Foundation and an NIMH grant MH44866 awarded to P. S. Goldman-Rakic.

\section{REFERENCES}

Angrist B (1994): Amphetamine psychosis: Clinical variations of the syndrome. In Cho AK, Segal DS (eds), Amphetamine and its Analogs: Psychopharmacology, Toxicology, and Abuse. San Diego, Academic Press, pp 387-414

Antelman SM (1994): Time-dependent sensitization in animals: A possible model of multiple channel sensitivity in humans. Toxicol Ind Health 10:335-342

Antelman SM, Caggiula AR (1996): Oscillation follows drug sensitization: Implications. Crit Rev Neurobiol 10:101117

Badiani A, Anagnostaras SG, Robinson TE (1995a): The development of sensitization to the psychomotor stimu- lant effects of amphetamine is enhanced in a novel environment. Psychopharmacology (Berl) 117:443-452

Badiani A, Browman KE, Robinson TE (1995b): Influence of novel versus home environments on sensitization to the psychomotor stimulant effects of cocaine and amphetamine. Brain Res 674:291-298

Badiani A, Camp DM, Robinson TE (1997): Enduring enhancement of amphetamine sensitization by drugassociated environment stimuli. J Pharmacol Exp Ther 282:787-794

Beatty WW, Holzer GA (1978): Sex differences in stereotyped behavior in the rat. Pharmacol Biochem Beh 9:777-785

Becker JB, Robinson TE, Lorenz KA (1982): Sex differences and estrous cycle variations in amphetamine-elicited rotational behavior. Eur J Pharmacol 80:65-72

Benes FM, McSparren J, Bird ED, Vincent SL, SanGiovanni JP (1991): Deficits in small interneurons in prefrontal and anterior cingulate cortex of schizophrenic and schizoaffective patients. Arch Gen Psychiatr 48:9961001

Bickerdike MJ, Abercrombie ED (1997): Striatal acetylcholine release correlates with behavioral sensitization in rats withdrawn from chronic amphetamine. J Pharmacol Exp Ther 282:818-826

Cabib S, Puglisi-Allegra S, Genua C, Simon H, Le Moal M, Piazza PV (1996): Dose-dependent aversive and rewarding effects of amphetamine as revealed by a new place conditioning apparatus. Psychopharmacology (Berl) 125:92-96

Castner SA, Al-Tikriti MS, Baldwin RM, Seibyl JP, GoldmanRakic PS, Innis RB (in preparation): Effects of repeated low dose amphetamine exposure in rhesus monkeys. Behavior and SPECT imaging studies using [123I]-IBZM

Castner SA, Goldman-Rakic PS (in preparation): Enhancement of amphetamine-induced locomotion by prefrontal cortex lesions in monkeys

Chuang LW, Karoum F, Perlow MJ (1981): A study of the acute effects of amphetamine on the urinary excretion of biogenic amines and metabolites in monkeys. Br J Pharmacol 74:571-577

Dollfus S, Petit M (1995): Stability of positive and negative symptoms in schizophrenic patients: A 3-year follow-up study. Eur Psychiatr 10:228-236

Ellison G (1994): Stimulant-induced psychosis, the dopamine theory of schizophrenia, and the habenula. Brain Res Brain Res Rev 19:223-239

Ellison G, Eison MS, Huberman HS, Daniel F (1978): Longterm changes in dopaminergic innervation of caudate nucleus after continuous amphetamine administration. Science 201:276-278

Ellison G, Nielsen E, Lyon M (1981): Animal model of psychosis: Hallucinatory behaviors in monkeys during the late stage of continuous amphetamine intoxication. J Psychiatr Res 16:13-22

Ellison G, Ratan R (1982): The late stage following continuous amphetamine administration to rats is correlated with altered dopamine but not serotonin metabolism. Life Sci 31:771-777

Jentsch JD, Redmond DE Jr, Elsworth JD, Taylor JR, Young- 
ren KD, Roth RH (1997): Enduring cognitive deficits and cortical dopamine dysfunction in monkeys after longterm administration of phencyclidine. Science 277:953955

Jodogne C, Marinelli M, Le Moal M, Piazza PV (1994): Animals predisposed to develop amphetamine self-administration show higher susceptibility to develop contextual conditioning of both amphetamine-induced hyperlocomotion and sensitization. Brain Res 657:236-244

Kalivas PW, Stewart J (1991): Dopamine transmission in the initiation and expression of drug and stress induced sensitization of motor activity. Brain Res Rev 16:223-244

Krimer LS, Jakab RL, Goldman-Rakic PS (1997): Quantitative three-dimensional analysis of the catecholaminergic innervation of identified neurons in the macaque prefrontal cortex. J Neurosci 17:7450-7461

Kulhara P, Chandiramani K (1990): Positive and negative subtypes of schizophrenia: A follow-up study from India. Schizophr Res 3:107-16

Liddle PF, Friston KJ, Frith CD, Frackowiak RSJ (1992): Cerebral blood flow and mental processes in schizophrenia. Journal Royal Soc Med 85:224-227

Melega WP, Raleigh MJ, Stout DB, Lacan G, Huang SC, Phelps ME (1997): Recovery of striatal dopamine function after acute amphetamine- and methamphetamineinduced neurotoxicity in the vervet monkey. Brian Res 766:113-120

Paulson PE, Camp DM, Robinson TE (1991): Time course of transient behavioral depression and persistent behavioral sensitization in relation to regional brain monoamine concentrations during amphetamine withdrawal in rats. Psychopharmacology (Berl) 103:480-492

Post RM, Weiss SRB, Pert A (1992): Sensitization and kindling effects of chronic cocaine administration. In Lakoski JM, Galloway MP, White FJ (eds), Cocaine: Pharmacology, Physiology, and Clinical Strategies. Boca Raton, CRC Press, pp 115-161

Ridley RM, Baker HF, Owen F, Cross AJ, Crow TJ (1982): Behavioral and biochemical effects of chronic amphetamine treatment in the vervet monkey. Psychopharmacology (Berl) 78:245-251

Ridley RM, Baker HF, Owen F, Cross AJ, Crow TJ (1983): Behavioral and biochemical effects of chronic treatment with amphetamine in the vervet monkey. Neuropharmacology 22:551-554

Robinson TE, Becker JB (1986): Enduring changes in brain and behavior produced by chronic amphetamine administration: A review and evaluation of animal models of amphetamine psychosis. Brain Res 396:157-198

Robinson TE, Becker JB, Presty SK (1982a): Long-term facili- tation of amphetamine-induced rotational behavior and striatal dopamine release produced by a single exposure to amphetamine: Sex differences. Brain Res 253:231-241

Robinson TE, Camp DM, Jacknow DS, Becker JB (1982b): Sex differences and estrous cycle dependent variation in rotational behavior elicited by electrical stimulation of the mesostriatal dopamine system. Behav Brain Res 6: 273-287

Savageau MM, Beatty WW (1981): Gonadectomy and sex differences in the behavioral responses of amphetamine and apomorphine of rats. Pharmacol Biochem Behav $14: 17-23$

Segal DS, Kuczenski R (1994): Behavioral pharmacology of amphetamine. In Cho AK, Segal DS (eds), Amphetamine and its Analogs: Psychopharmacology, Toxicology, and Abuse. San Diego, Academic Press, pp 115-150

Selemon LD, Rajkowska G, Goldman-Rakic PS (1995): Abnormally high neuronal density in the schizophrenic cortex. A morphometric analysis of prefrontal area 9 and occipital area 17. Arch Gen Psychiatr 52:805-818

Selemon LD, Rajkowska G, Goldman-Rakic PS (1998): Elevated neuronal density in prefrontal area 46 in brains from schizophrenic patients: Application of a threedimensional sterologic counting method. J. Comp. Neurol. 392:402-412

Schlemmer RF, Young JE, Davis JM (1996): Stimulantinduced disruption of nonhuman primate social behavior and the psychopharmacology of schizophrenia. J Psychopharm 10:64-76

Stewart J (1992): Neurobiology of conditioning to drugs of abuse. Ann NY Acad Sci 654:335-346

Utera H (1966): Behavioral aberrations in methamphetamine-intoxicated animals and chemical correlates in the brain. In: Tokizane T, Schade J (eds) Progress in Brain Research, Vol. 21B, Correlative Neurosciences: Clinical Studies. New York, Elsevier

Villemagne V, Yuan J, Wong DF, Dannals RF, Hatzidimitriou G, Mathews WB, Ravert HT, Musachio J, McCann UD, Ricaurte GA (1998): Brain dopamine neurotoxicity in baboons treated with doses of methamphetamine comparable to those recreationally abused by humans: Evidence from [11C]WIN-35,428 positron emission tomography studies and direct in vitro determinations. J Neurosci 18:419-427

Wilson JM, Kalasinsky KS, Levey AI, Bergeron C, Reiber G, Anthony RM, Schmunk GA, Shannak K, Haycock JW, Kish SJ (1996): Striatal dopamine nerve terminal markers in human, chronic methamphetamine users. Nat Med 2:699-703 